\title{
INSTITUTIONALIZING VIRTUAL REALITY BASED CONSTRUCTION PROFESSIONAL TRAINING
}

\author{
PETER S.P. WONG, ABRAM HOFFMAN, SHERMAN C.P. CHEUNG, and RON \\ WAKEFIELD \\ School of Property, Construction and Project Management, RMIT University, Melbourne, \\ Australia
}

\begin{abstract}
Applying Virtual Reality (VR) in construction professional training has been advocated as an effective method to improve learner's cognition. However, there has been a lack of a systematic approach in VR-based training in the construction context. This study aims to develop a framework to institutionalize VR-based construction professional training design. Virtual Generation and Experience Road Map (VGERM) was adopted in the development of the mobile VR app for use in teaching substructure in an undergraduate construction technology course. A mobile VR app was developed by using a Unity-based platform, namely EduVenture. Procedures of the VR app development were articulated with an aim to demonstrate how the proposed framework can be utilized in fostering knowledge and skills transfer. Feedback of the users was collected through the Course Experience Survey. Findings of this study help gain a better understanding of the key areas to foster the benefits of VR for efficient use within professional construction training.
\end{abstract}

Keywords: EduVenture, Undergraduate construction technology course, VGERM, 360-degree panoramic image.

\section{INTRODUCTION}

Every industry has its specific skill set that their workforce should equip with. In the construction engineering sector, one of the most notable skills should be understanding and interpreting construction drawings into operational processes and practices (Pham et al. 2018). Without relevant work experience, learners usually encounter difficulties when they were asked to base on learning materials that are mainly two-dimensional drawings/pictures to delineate threedimensional objects in the construction sites. Moreover, construction drawings and models are the intellectual properties of the designers and developers. Without the kind donations from these companies, trainers often find it difficult to include updated construction drawings as live examples in their courses (Arashpour and Aranda-Mena 2017).

Furthermore, trainers also face challenges in gaining access to construction sites (Park et al. 2016). Particularly, the presence of a specific material, element, or construction process can begin and complete within a small window of minutes when site visits cannot be arranged (Goedert et al. 2011). The situation has become more acute when COVID-19 disrupts the conventional ways of professional training through face-to-face lectures or workshops. The social distancing rules also eliminated opportunities for construction site visits.

In this aspect, applying Virtual Reality (VR) in construction professional training has been advocated as an effective method to improve learner's cognition (Li et al. 2018). VR provides a 
new instructional element to facilitate learners to process information actively and practice the target skills (Wang et al. 2018). The use of VR fosters blended learning that integrates real-life site environment in professional training. VR technology has reached the maturity that can be used for knowledge and practical skills transfer (Ahmed 2019). Literature in industrial design, medical research and computer gaming envisaged positive results in applying VR in professional training (Li et al., 2018). However, the optimistic views should be read in a due caveat that successful implementation of VR in professional training is mostly reported from scholars in other sectors (Ahmed 2019). This study aims to develop a framework to institutionalize VRbased construction professional training design. The framework is then utilized to develop a VR app for use in an undergraduate construction technology course in Australia.

\section{DEVELOPMENT OF FRAMEWORK TO INSTITUTIONALIZE VR-BASED CONSTRUCTION PROFESSIONAL TRAINING}

VR can be defined as a development of simulations and generated models that sense the user's position, enabling interactivity and navigation through sensory feedback within a synthetic world (Ahmed 2019). There is no lack of literature on the use of VR in construction professional training. Through a comprehensive review, Wang et al. (2018) identified three types of VR techniques being applied in construction professional training: desktop-based VR, immersive VR, 3D game-based VR, and web-based VR.

Desktop-based VR does not provide a full sense of immersion but can display Building Information Modeling (BIM) on an ordinary personal computer work station without any tracking equipment as support (Meža et al. 2014). While it relies on the users' spatial perception abilities, the movement of 'walkthrough' in the non-immersive system was controlled by mouse and keyboard (Wang et al. 2018). Immersive VR techniques emphasize providing users access to an animated environment. Thabet et al. (2002) developed the Cave Automatic Virtual Environment (CAVE) to enable users to visualize BIM models/animated construction environment in the laboratory. Teizer et al. (2013) created several animated 3D models of the existing training facility with Sketchup and 3D Studio Max data. Users are equipped with an Ultra-Wideband (UWB) tag so that all their locations are tracked and recorded during the virtual visits. 3D gamebased models stressed on enabling users to interact with the 3D models. Goedert et al. (2011) developed a virtual interactive construction education (VICE) platform which provided gamebased safety training through the use of modeling and simulation. Li et al. (2012) developed a multi-user virtual safety training system (MVSTS) for tower crane dismantlement. The system is not only capable of connecting computers together (automatically or manually by providing a suitable IP address) but also data synchronism between all the connected computers.

The above three types of VR techniques have limitations in reflecting physical world visibility and user-device adaptability. To overcome this hurdle, Pham et al. (2018) applied webbased VR technology in construction safety education. They applied web-based panoramic virtual photo reality technology. A photo reality scene can be captured with portable devices, such as the Samsung Gear 360. Furthermore, the recent proliferation of wearable devices, such as VR-glasses, provides major potential applications to support both the industry and education. However, photo reality technology by itself cannot provide float object interactions. Further VR app development is needed to enable users to interact with the web-based panoramic virtual photos.

Previous studies have eluded to the benefits of VR in construction professional trainings; however, such has been exploratory in nature and results are centered around prototyping. Furthermore, research has presented VR holistically with little consideration towards the user- 
centred parameters to create, access, and interact with the virtual learning environment. A detailed approach through which the usability can be explored through a solid framework of qualitative metrics is necessary. In this aspect, this study adopted an approach proposed by Craig (2009) to develop a framework for construction professional training through the use of the Virtual Generation and Experience Road Map (VGERM). VGERM is proven effective in developing VR training in the entailment, medical, and defense fields (Craig 2009). It envisages that the creation of VR-based training applications requires 'Input', i.e., a synthesis of real-world and virtual data to create an immersive environment (Whyte and Nikolic 2018).

Furthermore, it also requires a device-based platform to get 'Access' to and provide 'Experience' under the immersive environment (Chinowsky 2014). To develop a fit-for-purpose VR-based training application, the 'Input' and 'Access \& Experience' mechanisms should operate conjunctively. The VGERM developed for this study is presented in Figure 1.

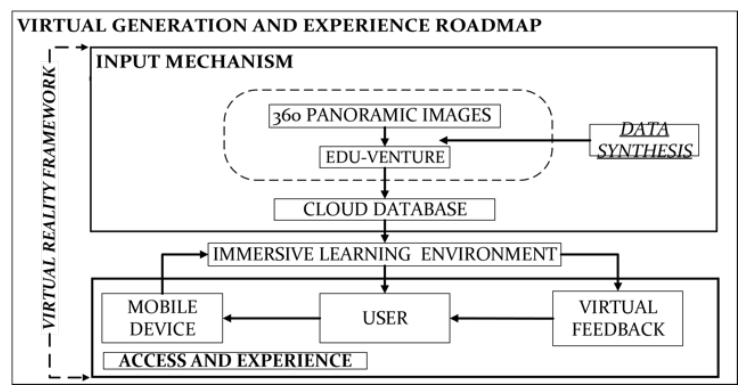

Figure 1. Virtual Generation and Experience Road Map designed for construction professional training.

\section{METHODOLOGY}

The Methodology section of this paper articulates how VGERM is applied in the development of the VR app for use in construction professional training. Regarding the Input mechanism, it involves collecting and synthesizing real and virtual data. In this connection, construction site visits were arranged to capture relevant images to be included in the VR app. In order to generate a VR-based learning environment using 360-degree panoramic images, construction-specific data must be collected using an appropriate image capturing device. The RICOH THETA V 360degree camera was selected to capture a 360-degree image of on-site construction environments. The selection of the RICOH THETA V 390-degree camera was based upon its compact size of $45 \mathrm{~W} \times 130 \mathrm{~L} \times 22 \mathrm{H}$, allowing convenient transport to and around construction sites. In addition, a RICOH THETA V 360-degree camera includes a free-to-download feature, which provides a real-time view of the construction environment in 360 degrees before an image is captured. The Input mechanism within the VGERM only function to create an immersive learning experience using VR. Though users' experiences within the virtually built environment is dictated by the quality and accuracy of the virtual element atone to the real environment, immersion is only achievable through the Access and Feedback mechanisms (Henneberg 2017).

Regarding the Access and Experience mechanism, it involves app development. In this aspect, EduVenture is the most efficient system available to date capable of synthesizing 360degree panoramic images into a VR Bases environment. EduVenture is an online virtual learning platform for assisting institutions through the challenges associated with traditional delivery teaching material on a field excursion. The use of EduVenture allows trainers to provide an enhanced learning experience by translating outdoor learning materials into a VR-based environment (Centre for Learning Sciences and Technologies 2019). The cloud-based 
architecture of EduVenture allows producers to upload captured 360-degree images to EduVentures's online composer platform from any device. The EduVenture panoramic editing system enables the combination of a multitude of panoramic images to create an immersive learning environment within minimal cognitive and financial input (Centre for Learning Sciences and Technologies 2019). This study adopted EduVenture to develop a VR app for use in construction professional training.

\section{FINDINGS OF UTILIZING VGERM IN VR APP DEVELOPMENT: A CASE STUDY IN AUSTRALIA}

To demonstrate how the proposed VGERM framework can be applied in VR-based construction professional training design, a VR app namely "Sub-structure Basics" was developed. The VR app was then used in the tutorial of a course named "Structures and Materials 2" in a Year 3 construction undergraduate program in Australia. Feedback from the students was collected in class. "Sub-structure Basics" is identified as the topic because feedback from previous years indicate that students find it hard to delineate substructures of the buildings through reading 2-D drawings. For example, ground anchors and capping beams underground are usually presented in the elevation and sectional views from the 2-D drawings. Required construction procedures may not be easily understood without site visits. Furthermore, students also found it difficult to distinguish the difference between post-tensioned slabs and suspended slabs from drawings. In this connection, preparation meetings were held to develop a storyboard for the VR app. VR pictures that were required to be captioned on-site were identified. It was decided that the VR app would be developed as a walk-through immersive site visit with the following content: Scene 1: Capping beams and Ground anchors; Scene 2: Post-tensioned Slabs; Scene 3: Site Establishments; and Scene 4: Suspended Slabs.

Site pictures were then taken in a 10-story office tower development in Melbourne, Australia. Panoramic 360-degree images captured from the construction sites were then uploaded to the EduVenture platform. Based on the storyboard, the respective 360-degree panoramic images are uploaded in sequence. Under each of the pictures, labels and tags were added as the interactive elements. The labels and tags help the trainer to direct the learners to the spots of the pictures that need attention. A programming language called 'Unity' was used to determine when the labels and tags would appear when users get access to the relevant 360-degree panoramic image. The presence of the labels and tags and the duration of the appearance of each 360-degree panoramic image can be unlimited or timed based on the learning objective of trainer. The landing page of the VR app and immersive views of one of the scenes of this app are presented in Figures 2 and 3.

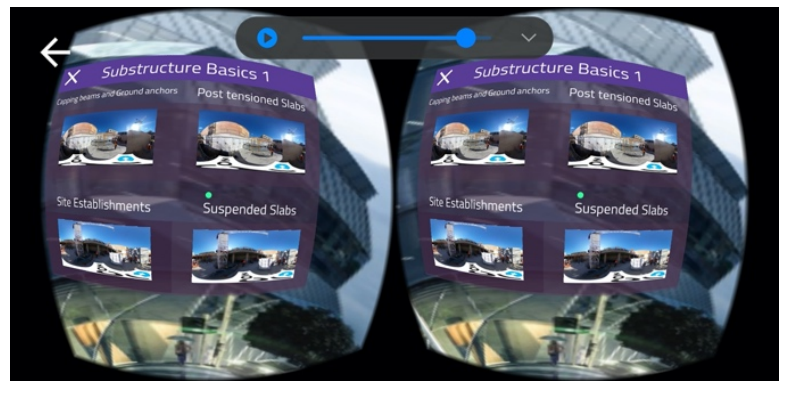

Figure 2. The landing page of the VR app. 


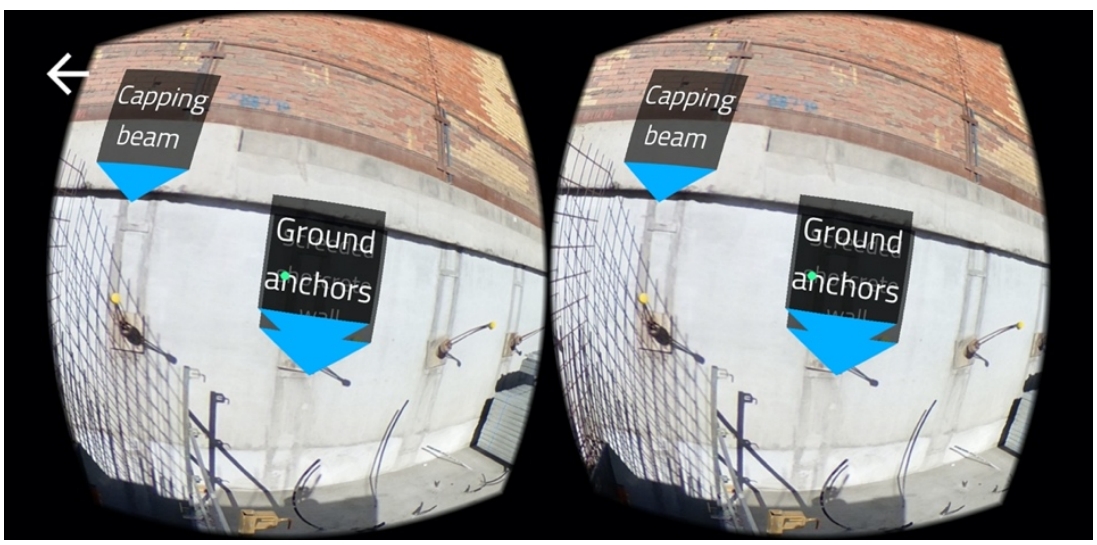

Figure 3. Immersive views of the VR app.

The VR app has been successfully delivered in class (refer Figure 4). Learners were generally satisfied with the immersive experience. Feedback was collected through the annual Course Experience Survey. The summary of students' feedback include the following:

- "The VR apps that show substructures and superstructures in class are fantastic. It really helps me to understand the construction process more thoroughly."

- "Thanks for the innovative ideas to bring the construction site experience to the classrooms. Substructure cannot be easily seen from existing buildings. Capturing the moment when it was being built is the best idea for knowledge transfer."

- "Combined with the VR pictures, I understand the respective BIM and drawings better."

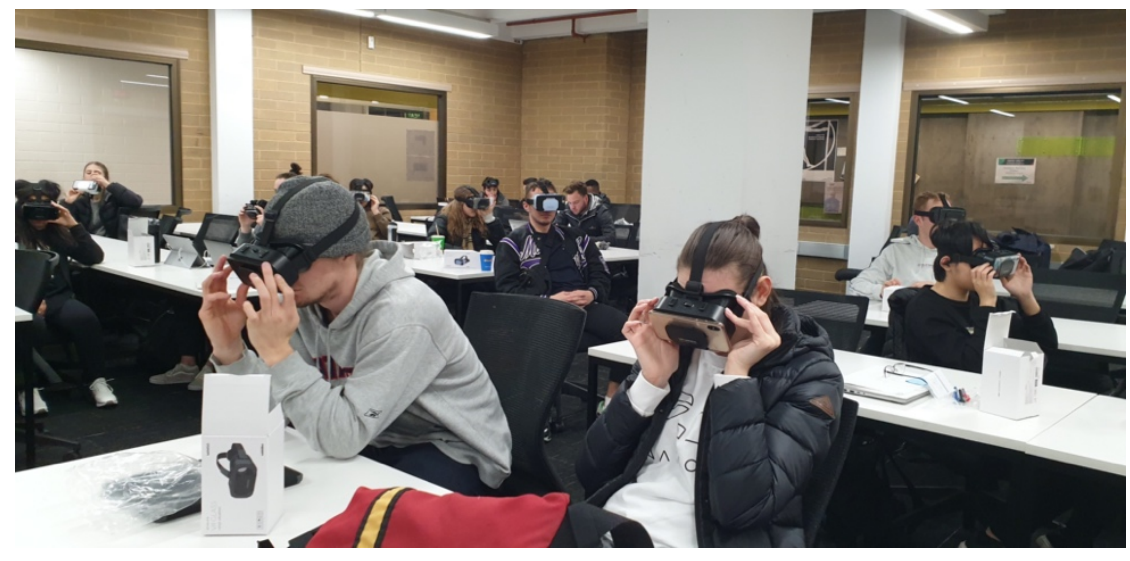

Figure 4. Using VR app in teaching substructure in class.

\section{CONCLUSION}

Researchers advocate the advantages of VR against traditional methods of delivering construction professional training. Despite the increased research in VR as a training application, there has been a lack of a framework to institutionalize VR-based construction professional training design. This study adopted the Virtual Generation and Experience Road Map (VGERM) to design a VR app for use in an undergraduate construction technology course. Procedures of VR apps development and the initial students' feedback were reported. The primary focus of this study is to produce an effective framework for developing VR-based professional training. The VR app 
"Substructure Basics" developed for the undergraduate construction students can be seen as a pilot study that demonstrates the application of this framework. Such findings shall provide future researchers with a better understanding of the key areas to foster the benefits of VR for efficient use within professional construction training.

\section{References}

Ahmed, S., A Review on Using Opportunities of Augmented Reality and Virtual Reality in Construction Project Management, Organization, Technology and Management in Construction, 11(1), 1839-1852, 2019.

Arashpour, M. and Aranda-Mena, G., Curriculum Renewal in Architecture, Engineering, and Construction Education: Visualizing Building Information Modeling Via Augmented Reality, in Pellicer, E., José, M., Víctor, A., Singh, A., and Yazdani, S., (eds), ISEC 2017: Resilient Structures and Sustainable Construction, ISEC Press, Spain, 1-6, 2018

Centre for Learning Sciences and Technologies, Introduction to the EduVenture System, 2019, retrieved from http://ev-cuhk.net/about.php on October 20, 2019.

Chinowsky, P., Construction Technology, 1st edn, Routledge, London, 2014.

Craig, A., Developing Virtual Reality Applications Foundations of Effective Design, Burlington, Mass : Morgan Kaufmann Publishers, Burlington. 2009.

Goedert, J., Cho, Y., Subramaniam, M., Guo, H., and Xiao, L., A Framework for Virtual Interactive Construction Education (VICE), Automation in Construction, 20(1), 76-87, 2011

Henneberg, S., Virtual Reality, 1st ed, Greenhaven Publishing, New York. 2017.

Li, X., Yi, W., Chi, H. L., Wang, X. and Chan, A., A Critical Review of Virtual and Augmented Reality (VR/AR) Applications in Construction Safety, Automation in Construction, 86(15), 150162, 2018.

Li, H., Chan, G., and Skitmore, M., Multiuser Virtual Safety Training System for Tower Crane Dismantlement', Journal of Computing in Civil Engineering, 26(5), 638-647, 2012.

Meža, S., Turk, Z., and Dolenc, M., Component Based Engineering of A Mobile BIM-Based Augmented Reality System, Automation in Construction, 42,1-12. 2014.

Park, S., Le, T, Pedro, A., and Lim, C., Interactive Building Anatomy Modeling for Experiential Building Construction Education, Journal of Professional Issues in Engineering Education and Practice, 142(3), 1-12, 2016.

Pham, H. C., Dao, N. N., Kim, J. U., Cho, S. G., and Park, C. S., Energy-Efficient Learning System Using Web-Based Panoramic Virtual Photoreality for Interactive Construction Safety Education, Sustainability, 10(7), 1-17, 2018.

Thabet, W., Shiratuddin, M. F., and Bowman, D., Virtual Reality in Construction: A ReviewVirtual Reality, in Construction, Engineering Computational Technology, 25-52, Saxe-Coburg Publications, 2002: ISBN 1-874672-17-2

Teizer, J., Cheng, T. and Fang, Y. H., Location Tracking and Data Visualization Technology to Advance Construction Ironworkers' Education and Training in Safety and Productivity, Automation in Construction, 35, 53-68. 2013.

Wang, C., Li, H., and Kho, Y., VR-Embedded BIM Immersive System for QS Engineering Education, Computer Applications in Engineering Education, 26(3), 626-641, 2018.

Whyte, J., and Nikolic, D., Virtual Reality and the Built Environment, 2nd ed., Routledge, London. 2018. 